\title{
ESTUDO DA OBTENÇÃO DE LIGANTES ASFÁLTICOS OBTIDO A PARTIR DO MATERIAL RESIDUAL GERADO NA ETAPA DE DESTILAÇÃO DO PLO*
}

\author{
Guilherme Silva Costa \\ Torben Ulisses da Silva Carvalho \\ Renan Correa Aranha ${ }^{2}$ \\ Rafaela Lima Lopes ${ }^{2}$ \\ Silvio Alex Pereira da Mota
}

\begin{abstract}
Resumo
A utilização de uma matéria prima renovável que possa substituir os asfaltos utilizados para pavimentação, provenientes do petróleo torna-se algo que pode ser viável ambientalmente. A produção renovável de bioprodutos através do craqueamento térmico de óleos vegetais gera um rejeito conhecido como produto líquido orgânico (PLO). O objetivo deste trabalho é obter uma metodologia de produção de ligantes asfálticos a partir do produto de fundo proveniente da etapa de destilação do PLO oriundo da reação de craqueamento do óleo de palma em uma unidade piloto de produção. Foram caracterizadas quatro amostras (produto de fundo sem tratamento térmico, produto de fundo com tratamento térmico a $375^{\circ} \mathrm{C}$ durante 15, 30 e 45 minutos) para obtenção da metodologia na qual os resultados seriam os mais aproximados dos valores específicos dos ligantes asfálticos derivados de petróleo. As análises dos dados possibilitaram observar a amostra com tratamento térmico a $375^{\circ} \mathrm{C}$ durante 45 minutos consumiu muito material, porém obtive resultados aproximados aos especificados pelo CAP 150-200.
\end{abstract}

Palavras-chave: Ligante asfáltico; Óleo de palma; PLO.

\section{STUDY OF ASPHALTIC BINDERS' OBTENTION FROM RESIDUAL MATERIAL GENERATED ON STAGE OF OLP DISTILLATION}

\begin{abstract}
The use of renewable raw materials that can replace the used asphalt paving, from petroleum becomes something that can be environmentally feasible. The renewable production of bio-products by thermal cracking of vegetable oils produces a waste product known as organic liquid product (OLP). The objective is to obtain a asphalt binders production methodology from the bottom product from the distillation stage of the OLP derived from the cracking reaction of palm oil in a pilot plant production. Four samples were characterized (bottom product without heat treatment, bottom product to heat treatment at $375^{\circ} \mathrm{C}$ for 15,30 and 45 minutes) to obtain the method in which results are the most approximate to the specific values of the asphalt binder derived from petroleum. Data analysis allowed to observe the sample with heat treatment at $375^{\circ} \mathrm{C}$ for 45 minutes consumed a lot of stuff, but got similar results to those specified by CAP 150-200.
\end{abstract}

Keywords: Asphalt binders; Palm oil; OLP.

1 Graduado em Engenharia de Materiais, Bacharel, Faculdade de Engenharia de Materiais, Universidade Federal do Sul e Sudeste do Pará, Marabá, Pará, Brasil.

2 Graduando em Engenharia de Materiais, Estudante, Faculdade de Engenharia de Materiais, Universidade Federal do Sul e Sudeste do Pará, Marabá, Pará, Brasil.

3 Graduado em Engenharia Química, Doutor, Faculdade de Engenharia de Materiais, Universidade Federal do Sul e Sudeste do Pará, Marabá, Pará, Brasil. 


\section{INTRODUÇÃO}

O setor de petróleo é um dos que mais causam impactos significativos no meio ambiente. Neste cenário despontam, com particular destaque, os óleos lubrificantes que geram significativos impactos ambientais, seja pelos efeitos produzidos em sua cadeia produtiva, seja devido a sua destinação após o uso [1]. Com isso, tem-se uma busca por vias mais benéficas ao meio ambiente de fabricação de subprodutos oriundos do petróleo (GLP, querosene, lubrificantes, etc.) a partir de uma matériaprima renovável.

Segundo Felici e Borges [2], um método alternativo para produção renovável de biocombustíveis é o craqueamento térmico de óleos vegetais, no qual consiste da quebra das moléculas em altas temperaturas, na presença ou não de catalisadores. O produto obtido via rota de craqueamento de óleos vegetais ou materiais residuais é um material líquido orgânico rico em hidrocarbonetos denominado Produto Líquido Orgânico ou PLO [3].

Segundo os dados do Sistema Nacional de Viação - SNV de 2014, existem, no Brasil, $1.691 .522 \mathrm{~km}$ de rodovias, dos quais apenas $203.599 \mathrm{~km}$ são pavimentados, isto é, $12 \%$ de malha. A Pesquisa CNT (Confederação Nacional de Transporte) de Rodovias avaliou, em 2014, 98.475 quilômetros de rodovias pavimentadas por todo o país. Em 62,1 \% da extensão total pesquisada, foram detectados algum tipo de deficiência no pavimento, na sinalização ou na geometria da via [4].

A partir dessa premissa, vê-se o compromisso de buscar um asfalto com características ideais além de um baixo custo de produção, visando a melhoria do processo de manutenção e construção de rodovias, aumentando o conforto e segurança dos motoristas.

Para realizar a separação das frações que constituem o PLO (biocombustíveis), é realizada a destilação fracionada, a qual consiste em uma operação térmica, controlada pelo equilíbrio líquido-vapor, utilizada na separação dos constituintes das espécies químicas de misturas líquidas homogêneas, com base nas diferenças de volatilidade dos componentes (temperatura de ebulição), através da adição de energia térmica (calor) [5,6].

Neste contexto este trabalho teve como foco a obtenção de uma metodologia de produção de ligantes asfálticos a partir do material residual proveniente da etapa de destilação do produto líquido orgânico (PLO) oriundo da reação de craqueamento do óleo de palma em uma unidade piloto de produção localizada no Laboratório de Engenharia Química da Universidade Federal do Pará.

\section{MATERIAIS E MÉTODOS}

A matéria-prima utilizada foi o produto líquido orgânico (PLO) proveniente do processo de craqueamento em escala piloto do óleo de palma realizado no Laboratório de Processos de Separação Térmica (TERMTEK/UFPA).

Foi realizado o processo de destilação em escala de bancada no Laboratório de Processos de Separações Térmicas (THERMTEK). Este sistema é composto por um balão de fundo redondo para acondicionamento do PLO, o qual é constituído de borosilicato com capacidade de $1 \mathrm{~L}$; por uma manta térmica marca Quimis modelo Q321A25 e potência de $315 \mathrm{~W}$, utilizada no aquecimento do PLO contido no balão volumétrico; por uma coluna de destilação do tipo Vigreux sem empacotamento e composta por seis estágios e acoplada a uma conexão (junta de 24/40) constituída de vidro borosilicato com finalidade de interligar a coluna Vigreux com uma das 
extremidades do sistema de condensação; o qual era constituído por um condensador de casco e tubo feito de borosilicato, com um comprimento de $70 \mathrm{~cm}$; além de um funil de decantação constituído de borosilicato e capacidade de $250 \mathrm{~mL}$, utilizado para coleta do material destilado. Além destes o sistema era provido de um banho ultra termostático, conforme mostrado na Figura 1. Quanto à etapa de tratamento térmico para análise físico-química do PLO, esta foi desenvolvida em um forno mufla no Laboratório de Materiais Cerâmicos da Unifesspa.

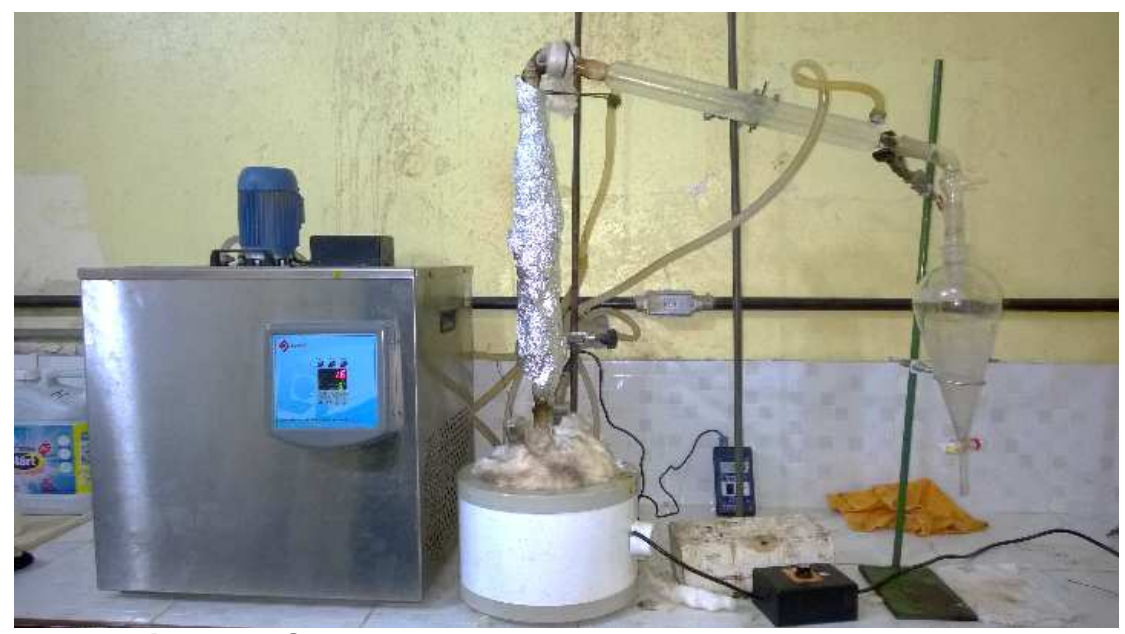

Figura 1. Sistema de destilação em escala de bancada.

Com o balão acoplado na manta, foi ajustado uma coluna Vigreux de seis estágios por onde os gases que saem do líquido em ebulição no balão destilador condensam e evaporam diversas vezes, durante esses estágios entre o líquido em ebulição e a cabeça de destilação. Esta coluna também estava ligada a uma conexão angular e nela um condensador de West, constituído de borosilicato, do tipo casco e tubo, com um passe no casco e um passe no tubo, onde foi acoplado um banho ultra termostático, que tinha função de condensar os gases provenientes do balão e passava pelos estágios da coluna acoplada no processo de destilação. Na outra extremidade do condensador foi encaixada outra conexão angular que ligou 0 condensador a um funil de decantação com capacidade de $1 \mathrm{~L}$ no qual tinha a função de acomodar dentro dele o produto destilado. Para diminuir a troca de calor com o ambiente, foi posto uma manta térmica e papel alumínio ao redor do balão e da coluna Vigreux.

Após a montagem do sistema de vidrarias necessárias, iniciou-se o processo de destilação com o banho ultra termostático a uma temperatura de $15^{\circ} \mathrm{C}$. Foi separado e pesada numa balança analítica, uma quantia de PLO; após pesado, o material foi despejado no balão de alimentação. Neste balão, foram inseridos uma rolha de alta resistência térmica em uma de suas entradas, e em outra foi acoplado o termopar. Com o banho na temperatura pré-estabelecida, foi ligado o sistema de aquecimento da manta aquecedora, com potência moderada.

O processo de destilação foi dividido em três bateladas ao todo, no qual os produtos eram aquecidos até chegarem às faixas de destilação correspondentes a cada componente derivado de petróleo: gasolina $\left(40^{\circ} \mathrm{C}-175^{\circ} \mathrm{C}\right)$, querosene $\left(175^{\circ} \mathrm{C}-\right.$ $\left.235^{\circ} \mathrm{C}\right)$, diesel leve $\left(235^{\circ} \mathrm{C}-305^{\circ} \mathrm{C}\right)$ e diesel pesado $\left(305^{\circ} \mathrm{C}-410^{\circ} \mathrm{C}\right)$. Quando eram alcançadas as temperaturas de cada fração, o material condensado se armazenava no funil de decantação e despejado em um béquer; posteriormente esses biocombustíveis foram retidos em recipientes adequados. Os dados do processo de destilação em cada batelada estão expostos na Tabela 1. 
Tabela 1. Destilação Fracionada do PLO

\begin{tabular}{cccc}
\hline & Batelada 1 & Batelada 2 & Batelada 3 \\
\hline Massa Balão $(\mathrm{g})$ & 353,28 & 402,72 & 402,00 \\
\hline Massa Béquer $(\mathrm{g})$ & 317,15 & 318,46 & 317,15 \\
\hline Massa PLO $(\mathrm{g})$ & $1.552,66$ & $1.390,17$ & $1.350,88$ \\
\hline Hora de Início $(\mathrm{h})$ & $11: 55$ & $15: 50$ & $15: 55$ \\
\hline Temperatura de Início $\left({ }^{\circ} \mathrm{C}\right)$ & 28,8 & 33,4 & 33,7 \\
\hline Hora Início Gotejamento $(\mathrm{h})$ & $12: 32$ & $16: 11$ & $16: 25$ \\
\hline Temperatura Início Gotejamento $\left({ }^{\circ} \mathrm{C}\right)$ & 154 & 160 & 152,4 \\
\hline
\end{tabular}

Com todas as faixas de combustíveis presentes no PLO coletadas, o sistema de destilação era desmontado a fim de armazenar o produto de fundo restante da destilação em recipientes convenientes. Tal produto é o material precursor a ser utilizado para produção de ligantes asfálticos e lubrificantes. Mesmo após o processo de destilação, o produto de fundo não apresentou uma viscosidade elevada para a sua utilização proposta, portanto foram realizados tratamento térmicos no material a fim de alcançar a viscosidade requerida.

De forma empírica, foi selecionada uma temperatura padrão de $375^{\circ} \mathrm{C}$, pois a $300^{\circ} \mathrm{C}$ a viscosidade continuava constante e a $410^{\circ} \mathrm{C}$ o material começava a inflamar e consumir parte de sua massa. Foram utilizados $40 \mathrm{~g}$ para cada tentativa no período de 15 minutos cada. Com isso, o material apresentou uma viscosidade boa para trabalho como ligante asfáltico, visto na Figura 2.

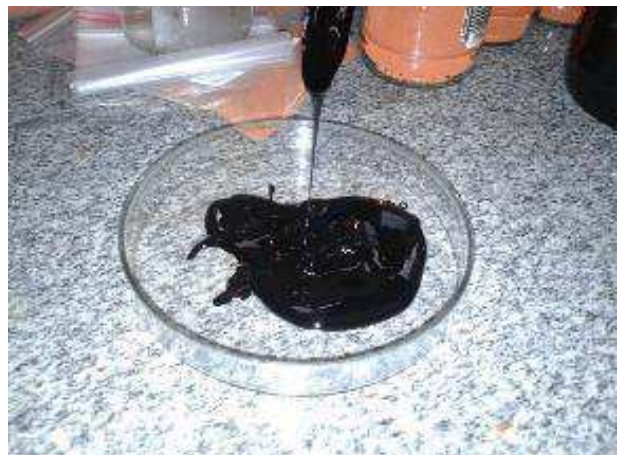

Figura 2. Amostra após o tratamento térmico a $375^{\circ} \mathrm{C}$ por 15 minutos.

Estabelecida a temperatura ideal para o processo, foram realizados os tratamentos térmicos em períodos de tempo de 15,30 e 45 minutos. O forno mufla que foi utilizado para esse processo foi ajustado dentro de uma capela para que os gases gerados no processo não fossem liberados no interior do laboratório, evitando desconforto e prejuízo à saúde pessoal. Foi pesado em uma balança $40 \mathrm{~g}$ de produto de fundo e postos em um cadinho cerâmico. Após passado os períodos de tempo estabelecidos, o cadinho era retirado do forno e resfriado a temperatura ambiente.

Tendo o material em sua viscosidade apta para a utilização em ligantes e lubrificantes, foram realizadas caracterizações físico-químicas no Laboratório de Química da Unifesspa, no Laboratório THERMTEK da UFPA e no Laboratório de Pavimentação da Empresa CONSTRUFOX localizada em Marabá/PA.

O Índice de Acidez foi determinado segundo a norma ABNT 14448/2013 [7], que é aplicável a produtos de petróleo, biodiesel e outros produtos derivados destes. $\mathrm{O}$ Índice de acidez foi calculado pela Equação 01, cuja unidade é, $\mathrm{mg} \mathrm{KOH} / \mathrm{g}$ de amostra. 


$$
\mathrm{IA}=\frac{(\mathrm{A}-\mathrm{B}) \times \mathrm{N} \times 56,1}{\mathrm{Ma}}
$$

Onde:

$A=$ Volume $(\mathrm{mL})$ de base padronizada gasto na titulação;

$B=$ Volume $(\mathrm{mL})$ de base padronizada gasto para titular o branco;

$\mathrm{N}=$ Normalidade da base padronizada;

$\mathrm{Ma}=$ Massa da amostra (g).

A viscosidade foi determinada segundo a norma ABNT NBR 14950/2003 [8], utilizando-se um viscosímetro Saybolt-Furol, marca CONTENCO, Modelo $\mathrm{n}^{\circ} \mathrm{I}-2025$, para 2 provas, com orifício furol $(\varnothing=3.15 \mathrm{~mm})$ para betume.

A densidade relativa foi medida segundo o método do picnômetro, usando-se um picnômetro de $10 \mathrm{ml}$ e utilizando como padrão água destilada. A densidade (massa especifica) foi calculada pela Equação 2.

$$
\rho=\frac{m_{1}}{m_{2}}
$$

Onde:

$\rho$ - densidade relativa;

$\mathrm{m}_{1}$ - massa da amostra $(\mathrm{g})$;

$\mathrm{m}_{2}$ - massa da $\mathrm{H}_{2} \mathrm{O}(\mathrm{g})$

O ponto de fulgor é um ensaio ligado à segurança de manuseio do asfalto durante o transporte, estocagem e usinagem. Representa a menor temperatura na qual os vapores emanados durante o aquecimento do material asfáltico se inflamam por contato com uma chama padronizada [9]. A norma utilizada para execução deste ensaio é a ABNT NBR 11341/2014 [10].

\section{RESULTADOS E DISCUSSÃO}

O PLO, produto líquido orgânico, oriundo do craqueamento em escala piloto no Laboratório de Processos de Separações Térmicas (THERMTEK/UFPA) usado nessa pesquisa foi caracterizado física e quimicamente, como visto na Tabela 2 [3].

Tabela 2. Resultados das análises físico-químicas dos produtos obtidos (PLO) com óleo de palma e carbonato de sódio como catalisador, em escala piloto

\begin{tabular}{cc}
\hline Propriedades & Valor \\
\hline Densidade $\mathrm{g} / \mathrm{cm}^{3}$ & 0,98 \\
\hline Viscosidade cSt & 4,96 \\
\hline Índice de acidez $\mathrm{mg} \mathrm{KOH} / \mathrm{g}$ & 39,00 \\
\hline Índice de saponificação $\mathrm{mg} \mathrm{KOH} / \mathrm{g}$ & 89,46 \\
\hline Índice de Éster $\mathrm{mg} \mathrm{KOH} / \mathrm{g}$ & 50,46 \\
\hline Índice de AGL \% & 19,62 \\
\hline Índice de refração & 1,45 \\
\hline Ponto de fulgor ${ }^{\circ} \mathrm{C}$ & 26,00 \\
\hline Corrosividade & $1^{\text {a }}$ \\
\hline Água e sedimentos (\%) & - \\
\hline Resíduo de carbono (\%) & 0,74 \\
\hline
\end{tabular}

Cada batelada do processo de destilação do PLO teve massas diferentes de biocombustível e produto fundo. A Tabela 3 exibe os dados de massa correspondente a cada fração e do produto de fundo das bateladas. 
Tabela 3. Massas das frações e produto de fundo das bateladas do processo de destilação do PLO

\begin{tabular}{cccccc}
\hline \multicolumn{2}{c}{ Batelada 1 } & \multicolumn{2}{c}{ Batelada 2 } & \multicolumn{2}{c}{ Batelada 3 } \\
\hline $\begin{array}{c}\text { Temperatura } \\
\left({ }^{\circ} \mathrm{C}\right)\end{array}$ & Massa $(\mathrm{g})$ & $\begin{array}{c}\text { Temperatura } \\
\left({ }^{\circ} \mathrm{C}\right)\end{array}$ & Massa $(\mathrm{g})$ & $\begin{array}{c}\text { Temperatura } \\
\left({ }^{\circ} \mathrm{C}\right)\end{array}$ & Massa $(\mathrm{g})$ \\
\hline $0-175$ & 10,21 & $0-175$ & 9,33 & $0-175$ & 14,32 \\
\hline $175-235$ & 72,58 & $175-235$ & 68,44 & $175-235$ & 46,63 \\
\hline $235-305$ & 215,71 & $235-305$ & 208,30 & $235-305$ & 195,75 \\
\hline $305-410$ & 562,11 & $305-410$ & 431,62 & $305-410$ & 273,33 \\
\hline $\mathrm{M}_{\text {Inicial }}(\mathrm{g})$ & 1552,6 & $\mathrm{M}_{\text {Inicial }}(\mathrm{g})$ & 1390,17 & $\mathrm{M}_{\text {Inicial }}(\mathrm{g})$ & 1350,88 \\
\hline $\mathrm{M}_{\text {Produto de Fundo }}$ & 545,44 & $\begin{array}{c}\mathrm{M}_{\text {Produto de Fundo }}(\mathrm{g}) \\
(\mathrm{g})\end{array}$ & 539,38 & $\begin{array}{c}\text { M Produto de Fundo } \\
(\mathrm{g})\end{array}$ & 704,49 \\
\hline Eficiência (\%) & 35,13 & Eficiência (\%) & 38,79 & Eficiência (\%) & 52,15 \\
\hline
\end{tabular}

O produto de fundo, originado do processo de destilação, antes do tratamento térmico, apresentou as características visualizadas na Tabela 4.

Tabela 4. Resultados das análises físico-químicas do produto de fundo antes do tratamento térmico

\begin{tabular}{cc}
\hline Ensaios & Valores \\
\hline Viscosidade Saybolt-Furol (s) & 100 \\
\hline $135^{\circ} \mathrm{C}$ & 60 \\
\hline $150^{\circ} \mathrm{C}$ & 13 \\
\hline $177^{\circ} \mathrm{C}$ & 0,9167 \\
\hline Densidade relativa & 37,31 \\
\hline Indice de acidez $(\mathrm{mgKOH} / \mathrm{g})$ & 200 \\
\hline Ponto de fulgor $\left({ }^{\circ} \mathrm{C}\right)$ &
\end{tabular}

Segundo Bernucci [9], a densidade do cimento asfáltico de petróleo (CAP) deve possuir um valor de 0,9990, valor próximo ao encontrado na amostra estudada. Em comparação à norma ABNT NBR-14950 [8], a amostra possui uma viscosidade Saybolt-Furol semelhante ao CAP $150-200$ a $135^{\circ} \mathrm{C}$; a $150^{\circ} \mathrm{C}$ a amostra se assemelha ao CAP 50-70; já à temperatura de $177^{\circ} \mathrm{C}$ ela se aproxima ao valor mínimo solicitado na especificação do CAP 85-100 e CAP 150-200 (15 a 60 segundos). A norma também aponta que o ponto de fulgor mínimo deve ser a $235^{\circ} \mathrm{C}$, porém o material avaliado apresenta valor abaixo do solicitado para todos os tipos de CAP's.

Para a realização do tratamento térmico da amostra de PLO, foram pesadas amostras de $40 \mathrm{~g}$ para cada período de tempo $\left(15,30\right.$ e 45 minutos) a $375^{\circ} \mathrm{C}$. A Tabela 5 exibe os rendimentos desses processos. Foi visto que os rendimentos não são satisfatórios, devido a estes serem menores que $50 \%$ da massa inicial.

Tabela 5. Rendimento do PLO durante o processo de tratamento térmico

\begin{tabular}{cccc}
\hline Amostras & Massa de Entrada (g) & Massa de Saída (g) & Rendimento (\%) \\
\hline Amostra 1 (15 minutos) & 40 & 18,3 & 45,75 \\
\hline Amostra 2 (30 minutos) & 40 & 14,7 & 36,75 \\
\hline Amostra 3 (45 minutos) & 40 & 12,2 & 30,5 \\
\hline
\end{tabular}

Após realizado o tratamento térmico no PLO, foram realizadas novas análises físicoquímicas que são visualizadas na Tabela 6. 
Tabela 6. Resultados das análises físico-químicas do produto de fundo após o tratamento térmico

\begin{tabular}{cccc}
\hline ENSAIOS & $\begin{array}{c}\text { AMOSTRA 1 } \\
(\mathbf{1 5} \text { } i n)\end{array}$ & $\begin{array}{c}\text { AMOSTRA 2 } \\
(\mathbf{3 0} \text { } \mathbf{~ i n})\end{array}$ & $\begin{array}{c}\text { AMOSTRA 3 } \\
\text { (45 min) }\end{array}$ \\
\hline Viscosidade Saybolt-Furol (s) & & & \\
\hline $135^{\circ} \mathrm{C}$ & - & 60 & 85 \\
\hline $150^{\circ} \mathrm{C}$ & - & 30 & 46 \\
\hline $177^{\circ} \mathrm{C}$ & - & 10 & 12 \\
\hline Densidade relativa & 0,9185 & 0,9233 & 0,9376 \\
\hline Índice de acidez (mgKOH/g) & 29,51 & 29,65 & 22,17 \\
\hline Ponto de fulgor $\left({ }^{\circ} \mathrm{C}\right)$ & 210 & 200 & 240 \\
\hline
\end{tabular}

Foi visto que houve um aumento na densidade relativa de nas três temperaturas de tratamento, porém nenhuma ficou acima da média proposta na norma $(0,9990)$. A amostra que mais obteve aproximação foi a Amostra 3. A Amostra 2 não atendeu a nenhuma especificação de CAP em nenhuma das temperaturas, além de seu ponto de fulgor estar abaixo do solicitado, semelhante ao caso da Amostra 1. No caso da Amostra 3, os valores de viscosidade atendem às especificações do CAP 150-200 em praticamente todas as faixas de temperatura, onde apenas o valor da amostra na temperatura de $177^{\circ} \mathrm{C}$ chega a ser aproximado. A Amostra 3 foi a única que atendeu ao valor solicitado de ponto de fulgor (acima de $235^{\circ} \mathrm{C}$ ).

\section{CONCLUSÃO}

Os resultados experimentais obtidos em função dos parâmetros operacionais estabelecidos para a produção do produto de fundo e das amostras 1, 2 e 3 e a correlação entre os valores da caracterização físico-química realizadas permitiram concluir que apenas os valores obtidos na amostra $3\left(375^{\circ} \mathrm{C} / 45 \mathrm{~min}\right.$.) corresponderam aos mesmos valores especificados pelo CAP 150-200; e as demais amostras não atenderam os valores mínimos exigidos para ser classificado como ligante asfáltico.

Porém a partir da análise do rendimento na etapa de tratamento térmico revela que a produção desta amostra requer grande quantidade de produto de fundo produzido, o que deixa a amostra com certa inviabilidade de produção.

Pode-se afirmar que as amostras 1 e 2 comportaram-se com valores inferiores ao que pode-se classificar como um ligante asfáltico, porém a análise dos resultados e as características física e visuais mostram que essas amostras poderiam se enquadrar como um óleo lubrificante.

Em relação ao ponto de fulgor do material, pode-se concluir que os valores obtidos para o produto de fundo e as amostras 1 e 2 indicam que pode existir ainda materiais voláteis, que ao aquecidos, podem causar combustão; já a amostra 3 possui ponto de fulgor de acordo com a norma vigente.

Embora a amostra 3 atenda as especificações exigidas para classificação de um ligante asfáltico, essa amostra possui características do CAP 150-200, um ligante asfáltico proveniente da destilação do petróleo que possui uma viscosidade baixa em relação aos demais CAP's e tipicamente utilizado em tratamentos superficiais de estradas e rodovias. 


\section{REFERÊNCIAS}

1 Canchumani GAL. Óleos Lubrificantes Usados: um Estudo de Caso de Avaliação de Ciclo de Vida do Sistema de Rerrefino no Brasil. Rio de Janeiro: Universidade Federal do Rio de Janeiro; 2013.

2 Felici PHN, Borges JLB. Mini-usina de craqueamento térmico de óleos vegetais para comunidades de pequenos produtores: avaliação operacional de um protótipo. Semina: Ciências Agrárias. 2009; 30: 779-792.

3 Mota SAP. Craqueamento termo-catalítico de óleos vegetais em diferentes escalas de produção [tese de doutorado]. Belém: Universidade Federal do Pará; 2013.

4 CNT, SEST, SENAT. Pesquisa CNT de rodovias 2014: relatório gerencial. Brasília; 2014.

5 Ferreira CC. Estudo da Destilação Fracionada do Produto Líquido Orgânico Gerado no Craqueamento Termocatalítico do Óleo de Palma [trabalho de conclusão de curso]. Belém: Universidade Federal do Pará; 2013.

6 Geankoplis CJ. Transport Process Principles (Includes Units Operations). 4. ed. Prentice Hall; 2003.

7 Associação Brasileira de Normas Técnicas. NBR 14448: Óleos lubrificantes, produtos de petróleo e biodiesel - Determinação do número de acidez pelo método de titulação potenciométrica. Rio de Janeiro; 2013.

8 Associação Brasileira de Normas Técnicas. NBR 14950: Materiais betuminosos Determinação da viscosidade Saybolt-Furol. Rio de Janeiro; 2003.

9 Bernucci LB. Pavimentação Asfáltica: Formação Básica para Engenheiros. Rio de Janeiro: PETROBRAS/ABEDA; 2006. 